\title{
Yersinia intermedia
}

National Cancer Institute

\section{Source}

National Cancer Institute. Yersinia intermedia. NCI Thesaurus. Code C86857.

A species of facultatively anaerobic, Gram negative, rod shaped bacteria in the phylum Proteobacteria. This species is motile, positive for urease, indole, ornithine decarboxylase, pyrazinamidase, and citrate and negative for oxidase. It is able to ferment sucrose, cellobiose, sorbitol, rhamnose, sorbose, raffinose, and melibiose. Y. intermedia is found in aqueous environments and is a rare cause of gastrointestinal infections. 